\title{
Frequency of Bcr-Abl Fusion Oncogene Splice Variants Associated with Chronic Myeloid Leukemia (CML)
}

\author{
Zafar Iqbal $^{1,2,3 \#}$, Fatima Manzoor ${ }^{1 *}$, Mudassar Iqbal ${ }^{1,4}$, Shahid Ali ${ }^{5}$, Nadeem Sheikh ${ }^{6}$, Mahwish Khan ${ }^{1,3}$, \\ Aamer Aleem $^{7}$, Tanveer Akhtar ${ }^{1}$
}

\begin{abstract}
${ }^{1}$ Molecular Genetic Pathology (MGP) Unit, Department of Pathology, College of Medicine and King Khalid University Hospital, King Saud University, Riyadh, Saudi Arabia; ${ }^{2}$ Hematology, Oncology and Pharmacogenetic Engineering Sciences (HOPES) Group, Health Sciences Research Laboratories, Faculty of Biological Sciences, Department of Zoology, University of the Punjab, Lahore, Pakistan; ${ }^{3}$ Functional Molecular Biology/Hematology and Oncology Group, Centre for Research in Molecular Medicine and Institute for Molecular Biology and Biotechnology, The University of Lahore, Lahore, Pakistan; ${ }^{4}$ Department of Medicine, Kyrgyz State Medical Academy, Bishkek, Kyrgyzstan; ${ }^{5}$ National Genetics Laboratory Lahore, Pakistan; ${ }^{6}$ Molecular Biology Laboratory, Department of Zoology, University of the Punjab, Lahore, Pakistan; ${ }^{7}$ Division of Hematology and Oncology, Department of Medicine, College of Medicine and King Khalid University Hospital, King Saud University, Riyadh, Saudi Arabia.

Email: "mianzafaram@yahoo.com, "djanmuhammad@ksu.edu.sa
\end{abstract}

Received April 9 ${ }^{\text {th }}, 2010$; revised April 2 ${ }^{\text {nd }}, 2011$; accepted April 15 ${ }^{\text {th }}, 2011$.

\begin{abstract}
$B C R-A B L$ fusion oncogene originates from the reciprocal translocation of chromosome 9 and $22 t(9 ; 22)(q 34 ; q 11)$. It translates a chimeric protein, p210, characterized by constitutive activation of its tyrosine kinase, which triggers leukemogenic pathways resulting in onset of chronic myeloid leukemia (CML). In CML, the classic fusion is b2a2 or b3a2 fusing exon 13 (b2) or exon 14 (b3) of BCR to exon 2 (a2) of ABL. The type of bcr/abl transcripts may be associated with different prognosis and hence useful in therapeutic plan. This study was conducted to calculate the frequency of these splice variants as the frequencies of different fusion oncogenes associated with leukaemia can vary in different geographical regions due to interplay of genetic variation in different ethnic populations, diverse environmental factors and living style. A very sensitive nested RT-PCR was established to detect BCR-ABL splice variants in CML. Sensitivity of RT-PCR assay was of the order of $10^{-6}$. Thirty CML patients were subjected to BCR-ABL analysis. Out of 30 Pakistani patients, 19 (64\%) expressed b3a2 while 11 (36\%) expressed b2a2 transcript. This shows that BCR-ABL splice variants differ in their frequencies which may have an effect on biology and implications for prognosis and management of BCR-ABL positive Leukemias.
\end{abstract}

Keywords: BCR-ABL Positive Leukemia, Leukemia Cytogenetics, Philadelphia Chromosome, Chronic Myeloid Leukemia, BCR-ABL Alternative Splicing, BCR-ABL Splice Variants, Leukemia Alternative Splicing, Pharmacogenetics

\section{Introduction}

Cytogenetically chronic myeloid leukemia (CML) is characterized by the presence of Philadelphia $(\mathrm{Ph})$ chromosome, the diagnostic hallmark of CML, which is present in majority of CML patients. It originates from the reciprocal translocation of chromosome 9 and $22 \mathrm{t}(9 ; 22)$ (q34;q11) [1]. This reciprocal translocation gives rise to $\mathrm{BCR}-\mathrm{ABL}$ fusion oncogene, which translates a chimeric

*Authors contributed equally to this work and thus share first authorship. protein, p210BCR-ABL that is characterized by constitutive activation of its tyrosine kinase activity. In CML, the classic fusion is $\mathrm{b} 2 \mathrm{a} 2$ or $\mathrm{b} 3 \mathrm{a} 2$ fusing exon 13 (b2) or exon 14 (b3) of BCR to exon 2 (a2) of ABL [2,3]. Both $\mathrm{b} 3 \mathrm{a} 2$ and $\mathrm{b} 2 \mathrm{a} 2$ transcripts can be formed as a result of alternative splicing. These transcripts lead to the production of an $8.5 \mathrm{~kb}$ transcript coding for a $210-\mathrm{KDa}$ (p210) chimeric protein $[4,5]$. This constitutively active cytoplasmic tyrosine kinase does not block differentiation, but enhances proliferation and viability of myeloid lineage cells and leads to development of CML [6]. 
Genetic abnormalities lead to formation of fusion oncogenes and this phenomenon is driven by the environmental factors and living style which differ in different geographical regions, the frequencies of different fusion oncogenes associated with leukaemia can vary in different ethnic groups [7], which can have a significant effect on the management and prognosis of this type of leukaemia $[8,9]$. This study was conducted to calculate the frequency of BCR-ABL gene splice variants associated with CML. RT-PCR (Reverse Transcriptase Polymerase Chain Reaction) was chosen as the method of choice to detect BCR-ABL gene as this technique is one of the most sensitive methods for this purpose.

\section{Materials and Methods}

\subsection{Sample Collection}

Blood samples of $30 \mathrm{CML}$ patients were collected from different hospitals of Lahore. Clinical features of the patients are given in Table 1. Samples were collected in EDTA vacutainer tubes as per manufacturer's instruction with patient number, age and time/date of collection written on the tubes. Sample collection and processing for analysis was always started within 24 hours to minimize mRNA degradation [10]. All the samples were stored at $20^{\circ} \mathrm{C}$. The procedure for isolation of RNA was adapted from Chomczynski and Sacchi with slight modification $[11,12]$.

\subsection{RNA Extraction and cDNA Synthesis}

Quantity of RNA was estimated spectrophotometrically [13], while the quality of RNA was checked by native

Table 1. Clinical features of CML patients.

\begin{tabular}{|c|c|}
\hline Characteristics & Patient Number $(n=30)$ \\
\hline Age (years) & $\begin{array}{c}\text { Mean }=35 \\
\text { Range }=12-70\end{array}$ \\
\hline $\begin{array}{c}\text { Gender } \\
\text { Male } \\
\text { Female }\end{array}$ & $\begin{array}{c}21 \\
9\end{array}$ \\
\hline Splenomegaly & 26 \\
\hline Hemoglobin $(<10 \mathrm{~g} / \mathrm{dL})$ & 16 \\
\hline $\begin{array}{c}\text { WBC Count }\left(/ \mathrm{mm}^{3}\right) \\
50,000-100,000 \\
>100,000\end{array}$ & $\begin{array}{c}5 \\
25\end{array}$ \\
\hline $\begin{array}{c}\text { Platelet Count }\left(/ \mathrm{mm}^{3}\right) \\
100,000-450,000 \\
>450,000\end{array}$ & $\begin{array}{c}22 \\
8\end{array}$ \\
\hline $\begin{array}{c}\text { Mode of Diagnosis } \\
\text { Ph+ } \\
\text { BCR-ABL+ }\end{array}$ & $\begin{array}{l}30 \\
30\end{array}$ \\
\hline
\end{tabular}

agarose gel electrophoresis and formaldehyde denaturing gel electrophoresis [14]. RNA was reverse-transcribed to cDNA for using as template in PCR reaction. RT-reaction protocol and other reaction conditions were adapted from Van-Dongen [15]. Briefly, $10 \mu \mathrm{L}$ of RNA was added to $10 \mu \mathrm{L}$ of RT-reaction mixture containing $5 \mathrm{X}$ RT buffer (20 mM Tris $\mathrm{HCl}, 50 \mathrm{mM} \mathrm{KCl}, \mathrm{pH} 8.3,10 \mathrm{mM}$ DTT), 10 mM dNTPs, $10 \mathrm{mM}$ random hexamer primers, RiboLock ${ }^{\mathrm{TM}}$ RNase inhibitor (20 units), M-MuLV Reverse Transcriptase (40 units) (Fermentas, USA) and DPCE-treated water. Reaction was carried out by incubating at room temperature for $10 \mathrm{~min}, 37^{\circ} \mathrm{C}$ for $60 \mathrm{~min}, 99^{\circ} \mathrm{C}$ for $3 \mathrm{~min}$ and held at $4^{\circ} \mathrm{C}$ in the last step in the PCR machine.

\subsection{RT-PCR Amplifications}

PCR primers and nested PCR protocols for the detection of BCR-ABL fusion gene in CML patients were adopted from Radich [16]. The sequences of primers are given in Table 2.

The cDNA product was PCR amplified in two rounds with $1 \mathrm{U} / \mu \mathrm{L}$ of Taq DNA Polymerase, $125 \mathrm{mM}$ primers, 10x PCR buffer with $\mathrm{KCl}, 25 \mathrm{mM} \mathrm{MgCl}_{2}$ and $10 \mathrm{mM}$ dNTP Mix. Sterile water was used as negative control. Thermal cycling conditions for nested PCR were: Preliminary denaturation at $95^{\circ} \mathrm{C}$ for 2 min followed by 35 cycles of denaturation of double stranded DNA at $95^{\circ} \mathrm{C}$ for $5 \mathrm{sec}$, annealing at $55^{\circ} \mathrm{C}$ for $10 \mathrm{sec}$ and extension at $72^{\circ} \mathrm{C}$ for $15 \mathrm{sec}$, followed by a final extension at $72^{\circ} \mathrm{C}$ for 3 minutes. Round 2 was carried out with the same conditions. The PCR products were run on a $2 \%$ agarose gel with ethidium bromide to analyze the size of the amplicons.

\section{Results}

Primer combinations used in amplification allowed to amplify both types of transcripts in a single reaction. Quality of RNA was analyzed on formaldehyde gel electrophoresis (Figure 1) and efficiency of cDNA synthesis on agarose gel electrophoresis. Two types of PCR products were detected as 305bp and 234bp for b3a2 and b2a2 respectively (Figure 2). The frequencies of both fusion transcripts were found to be $63.33 \%$ and $36.66 \%$ for $\mathrm{b} 3 \mathrm{a} 2$ and $\mathrm{b} 2 \mathrm{a} 2$ respectively. The sensitivity assay was

Table 2. Primers used for detection of fusion gene BCR-ABL in CML by RT-PCR.

\begin{tabular}{|c|c|c|}
\hline $\begin{array}{l}\text { PCR } \\
\text { Round }\end{array}$ & Primer & Primer Sequence $\left(5^{\prime}-3^{\prime}\right)$ \\
\hline \multirow[b]{2}{*}{$\mathbf{1}^{\text {st }}$ Round } & CML C & 5'-GAAGTGTTTCAGAAGCITCTCC-3' \\
\hline & CML D & 5'- TGATTATAGCCTAAGACCCGGA-3' \\
\hline \multirow{2}{*}{$2^{\text {nd }}$ Round } & CML A & 5'-TGGAGCTGCAGATGCTGACCAACTCG-3' \\
\hline & CML B & 5'-ATCTCCACTGGCCACAAAATCATACA-3' \\
\hline
\end{tabular}




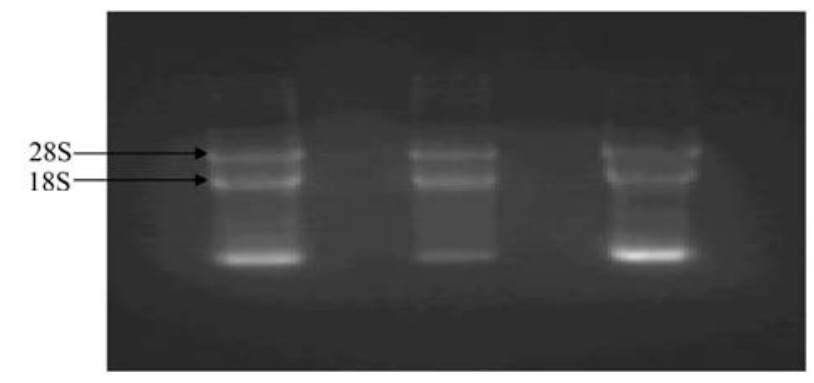

Figure 1. Formaldehyde gel showing bands of RNA from 3 different samples of CML patients.

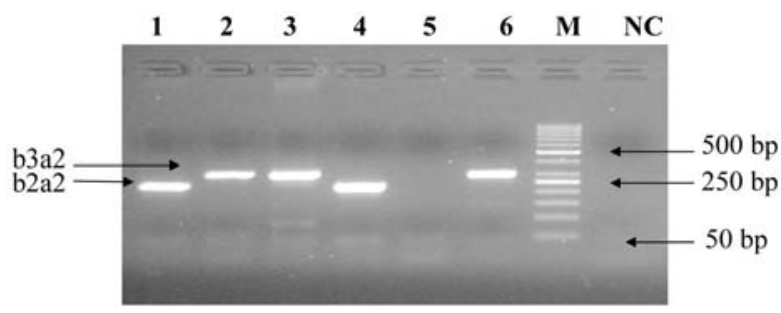

Figure 2. 2\% agarose gel containing Ethidium bromide showing two types of characteristics BCR-ABL transcripts b2a2 $(1,4)$ and b3a2 $(2,3,6)(234 b p$ and 305bp respectively), M: 50bp Ladder, NC: Negative Control.

also performed by generating 10 -fold serial dilutions to evaluate the sensitivity of RT-PCR for detection of these fusion transcripts. Using these dilutions, detection limit of the nested PCR was found upto $10^{-6}$ of cDNA for each sample (Figure 3).

\section{Discussion}

RT-PCR is one of the most sensitive techniques to detect BCR-ABL transcripts associated with CML [17]. Real time quantitative PCR is increasingly used to assess treatment response in patients with CML. When the level of residual leukaemia falls below the level of detection by bone marrow cytogenetic analysis, PCR based assays like the real time quantitative PCR or nested reverse transcriptase PCR are the methods of choice for further monitoring [18]. In this study nested PCR was opted as

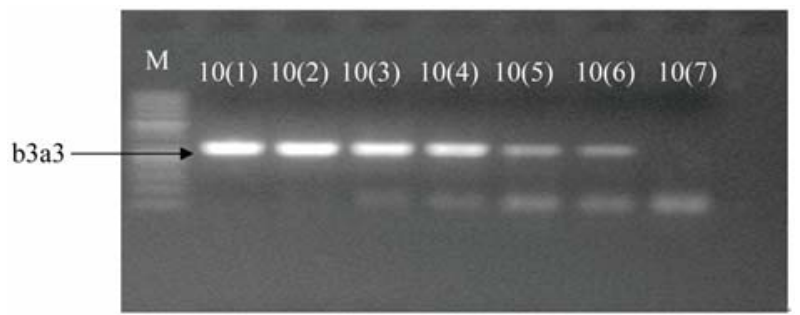

Figure 3. Amplification of BCR-ABL fusion transcript b3a2 (305 bp) from serial dilutions of cDNA $\left(10^{-0}-10^{-7}\right)$ showing a very good sensitivity of nested PCR for the detection of this transcript. $\mathrm{M} ; \mathbf{5 0}$ bp ladder. the method of choice due to its sensitivity to detect both b3a 2 and $\mathrm{b} 2 \mathrm{a} 2$ fusion transcripts in a single reaction. In the sensitivity assay of nested PCR, very high-quality results were obtained and this technique showed sensitivity upto $10^{-6}$.

In this study, the frequency of $\mathrm{b} 3 \mathrm{a} 2$ and $\mathrm{b} 2 \mathrm{a} 2$ was found to be $63.33 \%$ and $36.66 \%$ respectively. The frequency of $\mathrm{b} 3 \mathrm{a} 2$ is two times higher than $\mathrm{b} 2 \mathrm{a} 2$ with the ratio of $2: 1$ in our population. The coexpression of transcripts was not found in any of the patients. Spleen was grossly enlarged in most of the patients and mildly enlarged in some but without any correlation to transcript type. Data has been published about the frequency of different types of fusion oncogenes associated with acute lymphocytic leukemia (ALL) in Pakistan [19]. The frequency of BCR-ABL fusion oncogene in Pakistani childhood ALL patients was reported to be $49 \%$, which is higher as compared to other reports from around the world [19]. Frequency of different fusion oncogenes in Pakistani ALL patients is different from other geographic regions [9]. The frequency of fusion oncogenes associated with different leukemia types was compared with western populations and significant differences were observed due to geographical, racial and ethnic differences [7]. In a study carried out by Verschraegen, the frequencies of $\mathrm{b} 2 \mathrm{a} 2$ and $\mathrm{b} 3 \mathrm{a} 2$ transcripts were $30.2 \%$ and $67.9 \%$ respectively [20]. Reiter found the incidence of $\mathrm{b} 2 \mathrm{a} 2$ and $\mathrm{b} 3 \mathrm{a} 2$ transcripts in CML patients to be $31.6 \%$ and $68.4 \%$ respectively [21]. In Korean CML patients, frequency of b2a2 and b3a2 was collectively found to be $98.18 \%$, corresponding to $67.66 \%$ b3a2, and $32.34 \%$ b2a2 transcripts [22] where the number of patients with $\mathrm{b} 3 \mathrm{a} 2$ was twice the number of patients with b2a2. Frequencies of fusion transcripts in Iranian CML patients were found to be $21 \%$ and $62 \%$ for b2a2 and b3a 2 respectively [23]. The frequency of $\mathrm{b} 3 \mathrm{a} 2$ transcripts was found to be almost three times higher than that of $\mathrm{b} 2 \mathrm{a} 2$ [23].

Several authors have reported that CML patients with b2a2 BCR-ABL splice variants have a better prognosis and response to imatinib. De-Lemos et al. [24] reported that statistically significant difference was found for the levels of expression of transcripts b2a 2 and b3a2 at six months of imatinib treatment, which shows that b2a2 may have a better molecular response than b3a2. Verma et al. [25] reported that rare variants like ela2 have an inferior response to imatinib. Sharma et al. [26] found that $59 \%$ patients with b2a2 type achieved complete cytogenetic response (CGR) as compared to $28 \%$ patients with b3a2 $(p=0.04)$ while in 24 patients with minor or no CGR, $25 \%$ had b2a2 compared to $75 \%$ b3a 2 type ( $p=$ 0.04). Moreover, expression of BCR-ABL/ABL $\%$ was higher in $\mathrm{b} 3 \mathrm{a} 2$ patients compared to $\mathrm{b} 2 \mathrm{a} 2(p=0.120)$. 
They also found that pre-treatment characteristics like mean spleen size, mean hemoglobin, mean, and mean platelets counts were not significantly different in the b3a2 vs. b2a2 transcripts groups [26], which supports our findings. These observations highlight the need for more extensive studies in different ethnic groups on the role of different BCR-ABL splice variants in biology [27] and treatment response of the BCR-ABL positive leukemia patients, as acquired BCR-ABL point mutations and other factors associated with imatinib resistance do not explain the reason of imatinib resistance in all BCR-ABL positive patients [28-30]. Studies related to the differrences in clinical features and response to treatment in CML and philadelphia positive acute leukemia patients are specially required with the advent and FDA approval of other tyrosine kinase inhibitors (TKIs) like nilotinib and dasatinib for front-line treatment of BCR-ABL positive CML and ALL.

In conclusion, frequencies of BCR-ABL splice variants can vary in different geographical regions due to interplay of natural genetic variations in different ethnic populations, diverse environmental factors and living style. Moreover, the knowledge about the rate of occurrence of these transcripts associated with CML can be of very significance as it can lend a hand to further understand the pathobiology of $\mathrm{t}(9 ; 22)$-positive leukemic cells. Moreover, it will also assist in prognosis, treatment and management of these CML transcripts types.

\section{Acknowledgements}

This work was partially supported by the College of Medicine Research Center, Deanship of Scientific Research, King Saud University, Riyadh, Saudi Arabia, Research funding provided by Higher Education Commission Pakistan is also acknowledged.

\section{Conflict of Interest Statement}

The authors have no potential conflict of interest.

\section{REFERENCES}

[1] Q. Cardama and J. E. Cortes, "Chronic Myeloid Leukemia: Diagnosis and Treatment," Mayo Clinical Proceedings Journal, Vol. 81, No. 7, 2006, pp. 973-988.

[2] Y. Ben-Neriah, G. Q. Daley, A. M. Mes-Masson, O. N. Witte and D. Baltimore, "The Chronic Myelogenous Leukemia Specific P210 Protein is the Product of the Bcrabl Hybrid Gene," Science, Vol. 233, No. 4760, 1986, pp. 212-214. doi: $10.1126 /$ science. 3460176

[3] E. Shtivelman, B. Lifshitz, R. P. Gale and E. Canaani, "Fused Transcript of Abl and Bcr Genes in Chronic Myelogenous Leukaemia," Nature, Vol. 315, No. 6020, 1985, pp. 550-554. doi:10.1038/315550a0

[4] R. M. Arana-Trejo, E. R. Sanchez, G. Ignacio-Ibarra, E. B.
Fuente, O. Garces, E. G. Morales, M. C. Granados, R. O. Martinez, M. E. Rubio-Borja, L. S. Anaya, P. Herrera, J. D. Llamas and S. Kofman, "BCR/ABL P210, P190 and P230 Fusion Genes in 250 Mexican Patients with Chronic Myeloid Leukaemia," (CML) Clinical Labortary Haemotolgy, Vol. 24, No. 3, 2002, pp. 145-150. doi:10.1046/j.1365-2257.2002.00413.x

[5] B. D. Lichty, A. Keating, J. Callum, K. Yee, R. Croxford, G. Corpus, B. Nwachukwu, P. Kim, J. Guo and S. Kamel-Reid, "Expression of P210 and P190 BCR-ABL due to Alternative Splicing in Chronic Myelogenous Leukaemia," British Journal of Haematology, Vol. 103, No. 3, 1998, pp. 711-715. doi:10.1046/j.1365-2141.1998.01033.x

[6] R. Ren, "Mechanisms of BCR-ABL in the Pathogenesis of Chronic Myelogenous Leukaemia," Nature Review Cancer, Vol. 5, No. 3, 2005, pp. 172-183. doi: $10.1038 / \mathrm{nrc} 1567$

[7] Z. Iqbal, A. Tanveer, M. Iqbal, M. I. Naqvi, Z. Aziz, T. J. Gill, A.-U. Qayyam, A. S. Taj, M. Khalid, I. H. Shah, A. Jameel, M. Naeem, N. U. Rehman, M. Baig, M. Ferhan and A. M. Khalid, "First Comprehensive Report of Strong Interplay of Genetic and Environmental factors as well as High Degree of Ethnic and Geographical Variations in Biology of Leukemia as Manifested by Frequencies of Common Fusion Oncogenes of Prognostic Significance associated with Different Leukemic Subtypes in Pakistani population," In: Online Proceedings of 100th Annual Meeting, American Association of Cancer Research, Colorado. October 2009.

[8] H. Ariffin, S. P. Chen, C. S. Kwok, T. C. Quah, H. P. Lin and A. E. Yeoh, "Ethnic Differences in the Frequency of Subtypes of Childhood Acute Lymphoblastic Leukemia: Results of the Malaysia-Singapore Leukemia Study Group," Journal of Pediatric Hematology oncology, Vol. 29 , No. 1, 2007, pp. 27-31. doi:10.1097/MPH.0b013e318030ac4c

[9] Z. Iqbal, "Frequency of Chromosomal Abnormalities and Corrresponding Fusion Oncogenes in Acute Lympoblastic Leukemia (ALL) Patients of Pakistan and Its Implication in Differential Diagnosis and Prognosis of Leukaemia," Haematologica, Vol. 91, No. S3, 2006, p. 65.

[10] T. Hughes, M. Deininger, A. Hochhaus, S. Branford, J. Radich, J. Kaeda, M. Baccarani, J. Cortes, N. C. Cross, B. J. Druker, J. Gabert, D. Grimwade, R. Hehlmann, S. Kamel-Reid, J. H. Lipton, J. Longtine, G. Martinelli, G. Saglio, S. Soverini, W. Stock and J. M. Goldman, "Monitoring CML Patients Responding to Treatment with Tyrosine Kinase Inhibitors: Review and Recommendations for Harmonizing Current Methodology for Detecting BCR-ABL Transcripts and Kinase Domain Mutations and for Expressing Results," Blood, Vol. 108, No. 1, 2006, pp. 28-37. doi:10.1182/blood-2006-01-0092

[11] P. Chomczynski and N. Sacchi, "Single Step Method of RNA Isolation by Acid Guanidinium Thiocyanate-PhenolChloroform Extraction," Analytical of Biochemistry, Vol. 162 , No. 1, 1987, pp. 156-159.

doi:10.1016/0003-2697(87)90021-2 
[12] P. Chomczynski, "A Reagent for the Single-Step Simultaneous Isolation of RNA, DNA and Proteins from Cell and Tissue Samples," Biotechniques, Vol. 15, No. 3, 1993, pp. 532-537.

[13] J. A. Glasel, "Validity of Nucleic Acid Purities Monitored by A260/A280 Absorbance Ratios," Biotechniques, Vol. 18, No. 1, 1995, pp. 62-63.

[14] J. Sambrook and W. D. Russel, "Molecular Cloning," A Laboratory Manual, Cold Spring Harbor Laboratory Press, New York, 2001.

[15] J. J. Van-Dongen, E. A. Macintyre, J. A. Gabert, E. Delabesse, V. Rossi, G. Saglio and E. Gottardi, "Standardized RT-PCR Analysis of Fusion Genes Transcripts from Chromosome Aberrations in Acute Leukemia for Detection of Minimal Residual Disease," Report of the BIOMED-I Concerted Action: Investigation of Minimal Residual Disease in Acute Leukemia, Leukemia, Vol. 13, No. 12, 1999, pp. 1901-1928.

[16] J. P. Radich, G. Gehly, T. Gooley, E. Bryant, R. A. Clift, S. Collins, S. Edmands, J. Kirk, A. Lee and P. Kessler, "Polymerase Chain Reaction Detection of the BCR-ABL Fusion Transcript After Allogeneic Marrow Transplantation for Chronic Myeloid Leukemia: Results and Implications in 346 Patients," Blood, Vol. 85, No. 9, 1995, pp. 2632-2638.

[17] J. Q. Guo, H. Lin, H. Kantarjian, M. Talpaz, R. Champlin, M. Andreeff, A. Glassman and R. B. Arlinghaus, "Comparison of Competitive-Nested PCR and Real-Time PCR in Detecting BCR-ABL Fusion Transcripts in Chronic Myeloid Leukemia Patients," Leukemia, Vol. 16, No. 12, 2002, pp. 2447-2453. doi:10.1038/sj.leu.2402730

[18] S. Menif, S. Zarrouki, R. Jeddi, N. ben Alaya, Z. B. Ali, H. B. Abid, S. Hdeiji, M. Elloumi, A. Khlif, B. Meddeb and K. Dellagi, "A Quantitative Detection of Bcr-Abl Transcripts in Chronic Myeloid Leukemia," Pathologie Biologie, Vol. 57, No, 5, 2009, pp. 388-391. doi:10.1016/j.patbio.2007.12.010

[19] Z. Iqbal and A. Tanveer, "High Incidence of Bcr-Abl Fusion Oncogene in Pakistani Childhood Acute Lymphoid Leukaemia (ALL) Patients Reflects Ethnic Differences in Molecular Genetics of ALL," Haematologica, Vol. 91, No. S3, 2006, p. 65.

[20] C. F. Verschraegen, H. M. Kantarjian, C. Hirsch-Ginsberg, M. S. Lee, S. O’Brien, M. B. Rios, S. A. Stass, M. Keating and M. Talpaz, "The Breakpoint Cluster Region Site in Patients with Philadelphia Chromosome-Positive Chronic Myelogenous Leukemia," Clinical, Laboratory, and Prognostic Correlations, Cancer, Vol. 76, No. 6, 1995, pp. 992-997.

doi:10.1002/1097-0142(19950915)76:6<992::AID-CNCR 2820760612>3.0.CO;2-L

[21] E. Reiter, H. T. Greinix, S. Brugger, F. Keil, W. Rabitsch, C. Mannhalter, I. Schwarzinger, P. Höcker, G. Fischer, K. Dieckmann, W. Hinterberger, W. Linkesch, B. Schneider, K. Lechner and P. Kalhs, "Long-Term Follow-Up after allogeneic Stem Cell Transplantation for Chronic Myelogenous Leukemia," Bone Marrow Transplant, Vol. 22,
No. S4, 1998, pp. S86-S88.

[22] H. G. Goh, J. Y. Hwang, S. H. Kim, Y. H. Lee, Y. L. Kim and D. W. Kim, "Comprehensive Analysis of BCR-ABL Transcript Types in Korean CML Patients Using a Newly Developed Multiplex RT-PCR," Translational Research, Vol. 148, No. 1, 2006, pp. 249-256.

[23] M. Yaghmaie, S. H. Ghaffari, A. Ghavamzadeh, K. Alimoghaddam, M. Jahani, S. A. Mousavi, M. Irvani, B. Bahar and I. Bibordi, "Frequency of BCR-ABL Fusion Transcripts in Iranian Patients with Chronic Myeloid Leukemia," Archives of Iranian Medicine, Vol. 11, No. 3, 2008, pp. 247-251.

[24] J. A. de Lemos, C. M. de Oliveira, A. C. Scerni, A. Q. Bentes, A. C. Beltrão, I. R. Bentes, T. C. Azevedo, L. M. Maradei-Pereira, "Differential Molecular Response of the Transcripts B2A2 and B3A2 to Imatinib Mesylate in Chronic Myeloid Leukemia," Genetics and Molecular Research, Vol. 4, No. 4, 30 December 2005, pp. 803-811.

[25] D. Verma, H. M. Kantarjian, D. Jones, R. Luthra, G. Borthakur, S. Verstovsek, M. B. Rios and J. Cortes, "Chronic Myeloid Leukemia (CML) with P190 BCR-ABL: Analysis of Characteristics, Outcomes, and Prognostic Significance," Blood, Vol. 114, No. 11, 10 September 2009, pp. 2232-2235.

doi:10.1182/blood-2009-02-204693

[26] P. Sharma, L. Kumar, S. Mohanty and V. Kochupillai, "Response to Imatinib Mesylate in Chronic Myeloid Leukemia Patients with Variant BCR-ABL fusion Transcripts," Ann Hematology, Vol. 89, No. 3, March 2010, pp. 241-247. doi:10.1007/s00277-009-0822-7

[27] Z. Iqbal, M. Iqbal and T. Akhter, "Frequency of BCR-ABL Fusion Oncogene in Pakistani Childhood Acute Lymphoid Leukemia (ALL) Patients Reflects Ethnic Differences in Molecular Genetics of ALL," Journal of Pediatric Hematology/Oncology, Vol. 29, No. 8, August 2007, p. 585. doi:10.1097/MPH.0b013e3180f61bcf

[28] F. X. Gruber, T. Lundán, R. Goll, A. Silye, I. Mikkola, O. P. Rekvig, S. Knuutila, K. Remes, T. Gedde-Dahl, K. Porkka and H. Hjorth-Hansen, "BCR-ABL Isoforms Associated with Intrinsic or Acquired Resistance to Imatinib: More Heterogeneous than just ABL Kinase Domain Point Mutations?" Medical Oncology, 8 January 2011.

[29] Z. Iqbal, M. Iqbal, M. Akhtar, M. I. Naqvi, A. H. Tahir, T. J. Gill, et al., "Presence of Prior-to-Treatment BCR-ABL Mutations In CD34 + CD38-Stem Cells of Newly Diagnosed Chronic Phase CML Patients and Their Correlation with Imatinib Resistance: Implications of Cancer Pharmacogenomics and Pre-Therapeutic Genetic Testing in Personalized Treatment of BCR-ABL+Leukemia Blood," Vol. 116, No. 21, November 2010, p. 2278.

[30] C. M. Lucas, R. J. Harris, A. Giannoudis, A. Davies, K. Knight, S. J. Watmough, L. Wang, R. E. Clark, "Chronic Myeloid Leukemia Patients with the E13a2 BCR-ABL Fusion Transcript have Inferior Responses to Imatinib Compared to Patients with the E14a2 Transcript," Haematologica, Vol. 94, No. 10, October 2009, pp. 1362-1367. doi:10.3324/haematol.2009.009134 